\title{
Dignidade Humana e Umwelt: a Fundamentalidade Sistêmica do Princípio da Precaução Ambiental
}

\author{
Ricardo Augusto de Araújo Teixeira*
}

1 Introdução. 2 Pressupostos da Teoria dos Sistemas. 3 Dignidade Humana. 4 Conteúdo Jurídico do Princípio da Precaução ambiental. 5 Conclusão. Referências.

\section{RESUMO}

O presente artigo tem por objetivo investigar até que ponto a Teoria dos Sistemas sociais pode contribuir para o desenvolvimento da fundamentação principiológica do Direito Ambiental. Partindo de uma breve construção da estrutura da teoria dos sistemas - nos moldes luhmanianos -, chega-se ao estudo do princípio da precaução. Dentro deste contexto, objetiva-se ainda investigar se, dentro da concepção sistêmica, o referido princípio de Direito Ambiental encontra fundamentação na ideia de Dignidade Humana, reitora que é de todo o sistema jurídico e seus subsistemas.

Palavras-chave: Precaução. Principiologia Ambiental. Teoria dos Sistemas.

\section{INTRODUÇÃO}

E lá se foram vinte e sete anos desde a promulgação da atual Constituição brasileira. Em que pese todos os argumentos contrários, há um dado que parece permitir concluir que ela tem cumprido sua função: hoje um dos temas mais discutidos, dentro e fora do ambiente acadêmico jurídico, é a questão da efetividade dos Direitos Fundamentais.

Além disso, é notável a fertilidade que ela deu a nosso sistema jurídico, vez que possibilitou o aumento de demandas democraticamente feitas aos poderes constituídos, produzindo consideráveis avanços na Teoria do Direito, em especial no sentido da expansão das fronteiras do sistema jurídico que hoje recebe demandas indubitavelmente mais sofisticadas que aquelas da década de 1980 ou de décadas anteriores.

Um dos temas que vem sendo objeto da atenção de diversos pesquisadores é a efetividade da proteção ambiental, observada a partir de uma questão

* Mestre e Doutor Magna cum Laude em Direito Público pela PUC Minas. Especialista em Ciências Penais pelo IEC. Professor Adjunto de Direito Penal, Processual Penal e Criminologia da Universidade Federal de Lavras - UFLA. Coordenador do curso de pós-graduação em Controle, Detecção e Repressão Desvio de Recursos Públicos da ESAF-MG/UFLA. E-mail: ricardoaugustoteixeira@gmail.com. 
fundamental, qual seja, pode o direito ao meio-ambiente equilibrado ser tido, de fato, como direito fundamental? Pode ele ser fundamentado na ideia de dignidade humana, que tornou-se o referencial de fundamentalidade dos direitos particularmente após a II Guerra?

Há quem condicione a primeira pergunta a uma resposta afirmativa da segunda. Reinaldo Pereira da Silva, ${ }^{1}$ por exemplo, elenca algumas condições para que direitos sejam tidos por fundamentais, dentre elas que sejam "considerados essenciais ao resguardo e à promoção da dignidade humana”. ${ }^{2}$

Tal exigência impõe a complexa tarefa de definir o que se entende por dignidade humana, vez que a carga histórica do conceito nos guia a uma leitura individualista da ideia, notadamente a partir do célebre imperativo kantiano de que o homem é fim em si mesmo, não podendo, pois, ser feito meio para qualquer outro fim. Não obstante, ensina Franz Josef Wetz $z^{3}$ que:

Em geral a ideia de dignidade humana foi empregada de duas maneiras: primeiro, como demonstração de uma qualidade inata das pessoas, que foi chamada de conteúdo essencial. De acordo com essa ideia cada um possui em virtude da força de Ser humano, independente de seu comportamento ou das relações sociais, uma especial dignidade. Contudo, dignidade significou também uma tarefa organizacional, assim dependendo principalmente de nosso modo de vida e forma de comportamento se e em que extensão possuímos dignidade. Nesta correlação foi a dignidade considerada às vezes como mérito individual, às vezes como uma conquista da sociedade. (trad. nossa $\left.{ }^{4}\right)$.

Desta forma, o caminho a ser seguido neste artigo será, primeiramente, a identificação dos elementos típicos da Teoria dos Sistemas aplicada ao Direito, de forma a permitir uma construção adequada às suas complexas exigências metodológicas. Em seguida, será abordada a questão da "dignidade humana", numa tentativa de conformá-la com os limites que nos parecem adequados ao direito. Posteriormente, será abordado o chamado princípio da precaução ambiental (precautionary rule/Vorsorgeprinzip), partindo de uma reconstrução histórica, passando pela identificação dos problemas que envolve e, ao final, propondo um conceito adequado aos limites impostos tanto pela Teoria dos Sistemas quanto pela ideia de "dignidade humana".

\section{PRESSUPOSTOS DA TEORIA DOS SISTEMAS}

Desde logo, uma ressalva. O que é proposto neste momento é fazer uma breve descrição da forma como o Direito - e as demandas que a ele são feitas - podem ser repensados quando nos valemos do instrumental teórico da Teoria dos Sistemas, em geral seguindo as propostas de Niklas Luhmann. Todavia, dada a limitação de espaço deste texto, remetemos o leitor a nosso Direito Penal de Emergência, ${ }^{5}$ onde há um capítulo integralmente dedicado a mostrar e defender a operacionalização do Direito por meio da Teoria dos Sistemas. Assim sendo, aqui abordaremos apenas 
os aspectos primordiais, necessários ao desenvolvimento das ideias que virão na sequência. Um outro objetivo é familiarizar o leitor com a terminologia luhmaniana, por si só um desafio àqueles que desejam tomá-lo como referencial teórico.

Embora não seja uma construção originalmente feita para as Ciências Sociais - aplicadas ou não -, os princípios reitores da Teoria dos Sistemas permitem sua transposição para os mais diversos campos de investigação ${ }^{6}$.

Reconstruir a Teoria da Sociedade, a partir dos preceitos da Teoria dos Sistemas, foi a proposta de Niklas Luhmann ao assumir a titularidade na Universität Bielefeld. Eventualmente ele chegou também à teoria do Direito, locus este que nos interessa mais intensamente, e que atualmente é objeto de trabalho de diversos pesquisadores, sendo os mais destacados Günther Teubner, Andreas Fischer-Lescano e Andreas Philippopoulos-Mihalopoulos na Europa, Marcelo Neves, Juliana Neuenschwander e Leonel Severo Rocha no Brasil.

O aspecto mais elementar é uma mudança radical quanto ao que caracteriza a "sociedade" contemporânea?. Abandona-se a ideia weberiana de uma sociedade composta por pessoas, vez que centrada na ação, e assume-se a ideia de que a sociedade é comunicação ${ }^{8}$. E sendo ela comunicação ${ }^{9}$, é preciso repensar os demais institutos da teoria social, todos eles construídos sobre o pressuposto de que a sociedade é, em última análise, composta por pessoas.

Estabelecido este pressuposto, é preciso definir alguma forma de organização e simplificação de toda a "comunicação" que ocorre. Isso, na esteira de Luhmann, é feito por meio do desenvolvimento de sistemas. A ideia é simples, embora engenhosa. A vida social tem demandas as mais diversas. Para que tais demandas sejam respondidas, faz-se necessário que sistemas especializados surjam, até porque, do contrário, a desorganização de tanta informação (comunicação) geraria apenas caos. Desta feita, sistemas surgem conforme as demandas sociais exigem. A especialização - diferenciação ${ }^{10}$, na terminologia luhmaniana - consiste no desenvolvimento de sistemas específicos para lidar com demandas específicas, de forma a responder a elas de forma mais satisfatória, bem como organizar a comunicação e reduzir a complexidade da sociedade.

Pensemos, para exemplificar esta introdução, na necessidade de organizar a vida em sociedade. Num momento de menor complexidade social, bastava os vínculos familiares para o estabelecimento de condutas adequadas ou inadequadas, bem como para definições quanto a autoridades. Na medida em que a complexidade dos grupos sociais aumentou, novas formas de organização - de raízes ainda familiar - aparecem, como os clãs e fratrias. Com a insuficiência da autoridade familiar, é preciso uma fonte superior de estabilidade, que defina autoridades e noção de certo e errado, ou adequado/inadequado. Num primeiro momento podemos observar sistemas místico-morais, que evoluem para religiosos-morais, religiosos-morais-jurídicos até a eventual diferenciação de cada um deles, no momento em que a complexidade social não permite mais pensá-los como uma só coisa, e a cada um deles passam a ser dirigidas demandas particulares. 
Ao Direito compete a definição de licitude e ilicitude - uma sofisticação não exata da ideia de corretude e erro -, com isso garantindo expectativas comportamentais generalizáveis ${ }^{11}$.

Neste momento é possível inserir um novo dado, qual seja, os traços fundamentais de um "sistema social".

Um sistema se caracteriza por ser um grupo de comunicação organizado sob um código binário, que é operacionalmente fechado, mas cognitivamente aberto. Primeiro, serão abordadas as questões do código binário e a do fechamento operacional. Na sequência, trataremos da abertura cognitiva.

Um sistema necessita de operar fechado sob um código binário a fim de garantir sua diferenciação em relação aos demais sistemas, bem como para possibilitar a redução de complexidade ${ }^{12}$ da informação (e das demandas) com que ele trabalha. Assim, um sistema que opere de forma fechada sob um código estrito de comunicação responderá às demandas a ele endereçadas numa linguagem adequada ao referido código. Isso não significa que a comunicação - e o próprio sistema - não evolua, mas apenas que a evolução deve respeitar o código, sob risco de desdiferenciação e/ou de colonização por outro sistema.

Esta condição dos sistemas se desenvolveu a partir da ideia de autopoiese ${ }^{13}$, desenvolvida pelo biólogo chileno Humberto Maturana e adotada e adaptada por Luhmann para a Teoria dos Sistemas sociais. Investigando o surgindo da vida na Terra, Maturna identifica como momento definitivo aquele em que dentre as diversas combinações de elementos que ocorreram numa era pré-vida, há uma interação peculiar que se reproduz, diferenciando-se de seu ambiente. Neste momento, surge um sistema, uma unidade capaz de se reproduzir, e que é diferente de tudo que há em seu entorno ${ }^{14}$. Há aí o outro dualismo fundamental da Teoria dos Sistemas: Sistema/Ambiente.

Transposta para a teoria da sociedade, a ideia é que um sistema pode ser identificado quando ele reproduz sua comunicação obedecendo a um código binário específico e peculiar, que permite a ele desenvolver-se e diferenciar-se do resto das coisas, resto este agora chamado de ambiente ou entorno. É preciso notar que na terminologia original, Luhmann usou o termo Umwelt para designar o que em português foi chamado "ambiente", e que Umwelt também é o termo usualmente traduzido - na linguagem comum - por "meio ambiente", no sentido ecológico do termo. Daí o jogo de palavras do título: Umwelt é ambiente, entorno, mas também é meio ambiente. É, em síntese, o objeto principal deste texto.

O primeiro passo para identificar um sistema é, pois, identificar o código binário que rege determinadas comunicações. No caso do Direito, por exemplo, o código binário é "lícito/ilícito" ${ }^{15}$. Toda comunicação dentro do sistema jurídico se dá sob este parâmetro. Sempre que outro código é utilizado, há o risco de o sistema perder seu elemento de diferenciação. 
Diante deste risco, os sistemas devem operar de forma fechada ${ }^{16}$, isto é, não admitindo a entrada de comunicação construída sob outro código ${ }^{17}$. Não é possível, por exemplo, que o sistema jurídico opere com os códigos "poder/não-poder", ou "lucro/prejuízo", caracterizadores dos sistemas político e econômico, respectivamente. Os sistemas político e econômico são, para o Direito, ambiente, entorno.

Todavia, a complexidade da sociedade não permite que um sistema se isole dos demais. Um sistema que se fecha completamente tende a deixar de ser acionado, a deixar de receber demandas sociais, vez que a perda de contato tende a ter como resultado a incapacidade de responder às demandas. Quando isso ocorre, ou surge um novo sistema para lidar com tais demandas, ou elas terminam sendo tratadas por outro sistema, cuja comunicação evoluiu naquela direção.

No intuito de evitar o isolamento, os sistemas devem ser cognitivamente abertos, ou seja, dotados de um mecanismo que os permita dialogar com outros sistemas, isto é, com seu entorno. O nome que Luhmann deu a tal mecanismo é "acoplamento estrutural"18.

O acoplamento estrutural é um canal de comunicação existente entre dois sistemas ${ }^{19}$. Eventualmente uma estrutura pode funcionar como canal entre mais de um sistema. É o que ocorre, por exemplo, com a Constituição. A Constituição é o canal que permite a comunicação do Direito com o sistema político e com o sistema econômico. Cada um de forma individualizada.

Este "permitir a comunicação" entre sistemas diferentes significa que um sistema pode gerar perturbações a outro sistema, apesar de não operar sob o mesmo código binário. Logo, o mecanismo de acoplamento estrutural também funciona como um filtro/tradutor, que possibilita ao sistema transmutar a comunicação elaborada sob um outro código binário para uma comunicação dentro do código binário do sistema que foi por ela irritado ${ }^{20}$.

Neste momento o leitor, atento, pode estar se perguntando o que foi feito com as pessoas, afinal, não sendo elemento central da teoria da sociedade, elas devem aparecer em algum outro lugar, sob pena de toda a construção não ter nenhuma valia.

Luhmann considerava que "pessoas" é um termo que tem uma carga significante complexa demais para ser encaixado dentro da teoria dos sistemas. Por essa razão ele abandonou tal termo e passou a utilizar o termo "sistemas psíquicos" para identificar as "pessoas". Isto, pois, para Luhmann, do ponto de vista sistêmico, elas, as pessoas, precisam ser pensadas também como um sistema peculiar ${ }^{21}$. Isso gerou uma série de críticas. Todavia, dada a amplitude da questão, remetemos o leitor a outro texto, ${ }^{22}$ onde há uma aproximação completa da contenda.

É preciso ainda mourejar a questão dos "subsistemas". Subsistemas nada mais são que diferenciações que ocorrem dentro de sistemas sociais, a fim de responder a pedidos ainda mais específicos. A ideia é que o desenvolvimento da 
complexidade intrasistêmica pode levar à formação de especificações internas, direcionando demandas e respostas, e possibilitando reduzir a complexidade interna enquanto, simultaneamente, aumenta a qualidade das respostas dadas. Novamente o sistema jurídico é um bom exemplo. É claro que o código lícito/ ilícito é apto a lidar com todas as demandas, todavia, é salutar o desenvolvimento de subsistemas - direito penal, direito civil, direito tributário - a fim de permitir um ganho de sofisticação no discurso e, com isso, gerar melhores soluções para as demandas feitas.

Feita esta apresentação, é possível agora que pensemos nosso problema a partir deste instrumental teórico.

Dentro desta perspectiva, nossa tarefa de delimitar o conteúdo jurídico do Princípio da Precaução se torna menos complexa, pois ele deve ser visto, a priori, como um ato de comunicação que significa que havendo possibilidade/risco de repercussão ambiental negativa, o sistema jurídico decidirá a demanda determinando a realização da conduta que anule ou diminua tal risco, independentemente de maiores considerações. Não seria possível, por exemplo, sustentar que tal norma deve ser ponderada por razões econômicas - embora isso seja feito, e será visto adiante -, vez que isso seria a introdução de um argumento construído dentro de outro código binário, e mantido naquela linguagem, algo não tolerado pela Teoria dos Sistemas.

Em outras palavras, além de estabelecer uma reação previsível por parte do sistema jurídico, tal norma ainda impede que determinados argumentos sejam levados ao debate jurídico. É preciso, então, estudar as consequências desta reação sistêmica.

Quando um sistema é perturbado, três reações são possíveis. $O$ primeiro caso é aquele de uma irritação que o sistema percebe como irrelevante, a exemplo de um ato que não preenche as características necessárias para ser tido por comunicativamente relevante. $O$ exemplo jurídico típico desta situação são as condutas dos absolutamente incapazes: em regra, o Direito não reage a um ato por eles realizados, ainda que tenha forma jurídica, vez que o próprio sistema assume que os atos de tais "sistemas psíquicos" não oferecem a relevância comunicativa necessária a causar uma reação sistêmica.

O segundo caso é o da conduta que tenta fazer o sistema tomar uma decisão sob outro código binário. Por exemplo, uma decisão que afirmasse que, apesar do risco ambiental desconhecido, o risco deveria ser aceito em razão do provável retorno econômico que aquele ato terá. A reação sistêmica a esta situação é a exclusão ou anulação desta decisão, dada a violação do código binário. O sistema reage excluindo tal decisão em razão de ela oferecer um risco efetivo à própria existência do sistema, vez que a tomada de decisões dentro de outro código traz em si o risco de desdiferenciação, ou seja, que o sistema perca sua identidade, tornando-se parte de outro sistema, e o risco de colonização por outro sistema, isto é, que o sistema funcione como legitimador 
de decisões tomadas sob outro código, sem, contudo, respeitar efetivamente a estrutura e o código do sistema jurídico.

A terceira situação é aquela em que argumentos que respeitam o código binário do sistema são levantados, tornando o caso mais difícil. É o que ocorre, por exemplo, se um órgão de controle ambiental prévio afirma que determinado procedimento preencheu os requisitos de segurança ambiental. Nesse cenário deverá haver a evolução da comunicação intrasistêmica a fim de verificar se a solução dada se compatibiliza também com o princípio da precaução, vez que este é norma fundante do subsistem jurídico-ambiental. Se se perceber que o procedimento prévio de segurança foi pensado já a partir da ideia de precaução, a decisão tomada será aceita e o argumento incorporado ao desenvolvimento da comunicação do sistema. Se o procedimento de controle desconsiderar o que determina a precaução, por exemplo, por ser anterior a ela, a decisão tomada - que é um ato comunicativo deverá ser anulada ou reformada a fim de adequar-se à estrutura do sistema.

Outro aspecto que contribui para o desenvolvimento do tema abordado é a percepção da "dignidade humana" como elemento estrutural do sistema jurídico. Isto, porém, será abordado no próximo item.

\section{DIGNIDADE HUMANA}

A ideia de "dignidade humana" acabou tornando-se lugar comum no pensamento jurídico contemporâneo. Qualquer que seja a tese defendida, da inadequação das prisões à carga tributária, passando pela teoria dos contratos mercantis, em algum momento alguma parte da teoria acaba sendo justificada pelo postulado da "dignidade da pessoa humana". A pergunta que se faz é: é possível fundamentar a precaução ambiental em tal postulado? Como? E é possível com isso produzir argumentos que possam ser utilizados pelo sistema jurídico sem riscos de desdiferenciação e de colonização? A resposta nos parece afirmativa. Antes de chegar a ela, porém, é preciso revisitar a própria ideia de dignidade humana, a fim de compreendermos como ela assumiu o papel relevente que hoje tem.

A noção de dignidade tem uma história que remonta à Grécia clássica e às religiões antigas. Assim, Platão e Aristóteles, por exemplo, consideravam que "o ser humano se eleva por cima das outras entidades do mundo, em razão do fato de ter alma racional" 2324 . (trad. nossa ${ }^{25}$ ). Enquanto "no pensamento judeu, o ser humano se alça por cima de todas as criaturas, pelo fato de ser imagem e semelhança de Deus”. ${ }^{26}$ (trad. nossa ${ }^{27}$ ).

Ainda no pensamento clássico, os estóicos desenvolveram dois axiomas para expressar a importância do ser humano. "Akhonta", aquilo que tem valor, e "agatha", aquilo que tem dignidade. O ser humano tem valor, mas um valor que não pode ser medido, precificado. Daí, inclusive, a crítica dos estóicos a qualquer tipo de escravidão. ${ }^{28}$

Por outro lado, romanos e atenienses estranhavam a concepção de que a 
dignidade fosse algo com que se nasce. "Dignidade - dignitas et excellentia - era compreendida não como qualidade de nascença, mas sozinha como resultado de conquista individual e reconhecimento social”. ${ }^{29}$ (trad. nossa $\left.{ }^{30}\right)$.

Já no pensamento cristão a ideia de dignidade também é construída a partir da noção da criação à imagem e semelhança de Deus. "Como filho e semelhante a Deus, possui o homem um valor absoluto, por meio do qual ele se diferencia de todas as demais criaturas". ${ }^{31}$ (trad. nossa ${ }^{32}$ ).

Na filosofia moderna - dos séculos XVII e XVIII - o fundamento da dignidade dos homens é reconstruído sobre bases independentes de valores religiosos.

Assim fundamentou, por exemplo, Immanuel Kant no século XVIII a dignidade dos homens exclusivamente em sua própria consciência, liberdade, moralidade e razão - e não diretamente em sua semelhança a Deus e a sua colocação no mundo". ${ }^{33}$ (trad. nossa ${ }^{34}$ ).

O abandono da matriz religiosa permitiria ampliar o alcance da ideia, trabalhando-a a partir de outros pontos.

O professor da Universidade de Viena Peter Schaber, ${ }^{35}$ por exemplo, traz para a discussão a hipótese da dignidade como dependente de reconhecimento social.

[...] Para a atribuição da dignidade humana, diferentes fundamentos poderiam exercer algum papel. Assim, a circunstância relevante poderia ser que nós nos sintamos conectados aos outros, ou que eles pertençam à mesma espécie. (...) Esta sugestão não diz nada sobre onde o limite para a atribuição de dignidade deve ser movida. Esta demarcação de fronteiras seria muito mais dependente de considerações tidas por relevantes socialmente. (...). ${ }^{36}$ (trad. nossa $\left.{ }^{37}\right)$.

De início é preciso observar que tal sugestão é falha em identificar as origens históricas da ideia de dignidade humana. Outro problema, que o próprio Peter Schaber aponta, seria o risco de que a atribuição de dignidade se tornasse algo puramente arbitrário (ein Akt der Willkür zu werden), podendo ser ou não atribuida a partir de critérios inconsistentes. Outra questão posta é: o que legitimaria aos homens atribuirem-se dignidade reciprocamente, mas não atribuí-la a outros seres? Quais seriam as qualidades relevantes para a atribuição de dignidade? ${ }^{38}$

Diante de tais questionamentos, ele põe em discussão outra ideia, dada por Joel Feinberg, de que a dignidade deva/possa ser compreendida como a habilidade de fazer demandas e buscar seus direitos. "Deste modo a dignidade inata dos homens não seria dependente de reconhecimento social por parte de homens portadores de dignidade, mas da qualidade de ter tal habilidade" ${ }^{39}$ (trad. nossa $\left.{ }^{40}\right)$.

O próprio Schaber ${ }^{41}$ repudia a ideia de Feinberg por duas razões. A primeira seria o fato de que, assumida tal sugestão, a dignidade seria atingida não quando uma pessoa fosse humilhada ou maltratada, mas sim quando tivesse sua possibilidade de fazer demandas judiciais suprimida, o que é contraintuitivo. Ainda, 
pois esta sugestão retira a dignidade inata daqueles que não tem e eventualmente jamais terão capacidade de, pessoalmente, perseguir seus direitos, como é o caso das crianças e dos que nosso sistema chama "absolutamente incapazes".

Dada a insuficiência dos critérios apresentados até o momento, ainda seguindo Schaber, ${ }^{42}$ outra proposta deve ser analisada: a da "dignidade humana como direito a não ser humilhado" ${ }^{43}$.

Esta proposta será analisada a partir de casos paradigmáticos em que a dignidade é atingida a partir de diferentes tipos de humilhação, notadamente a tortura sistemática (Regel Folter) e uma vida em pobreza absoluta (ein Leben in absoluter Armut).

Ambas as situações impedem ou dificultam severamente que a pessoa faça uso daqueles atributos que nos diferenciam dos demais seres, como nossa liberdade, nossa noção de moralidade e nossa razão.

A contemplação destes exemplos paradigmáticos de violação da dignidade sugere a seguinte concepção de dignidade humana: a dignidade humana não é um bem físico, mas uma demanda moral, que é violada se uma pessoa for humilhada. Atribuir dignidade a um homem significa, por consequência, conferir a ele o direito moral a não ser humilhado. Cada pessoa tem, porque e enquanto compreendido como portador de dignidade humana, uma busca qualificada por ser tratada pelos demais de uma determinada forma e respectivamente de poder viver de uma forma específica. ${ }^{44}\left(\right.$ trad. nossa $\left.{ }^{45}\right)$.

O conceito acima, ao final, parece indicar uma correlação - talvez mesmo uma correspondência - entre as ideias de dignidade humana e autonomia (capacidade de autodeterminação) e/ou respeito próprio (Selbstachtung).

Neste ponto é possível responder à questão inicial quanto a possibilidade de se fundamentar a proteção ambiental na ideia de dignidade humana. Mesmo seguindo a sugestão de Krystian Complak ${ }^{46}$ de que a dignidade humana deve ser utilizada para fundamentar apenas os aspectos mais fundamentais dos direitos humanos, entendemos cabível, aliás, imperativo fundamentar nela a exigência de proteção ambiental.

E assim defendemos, pois é indiscutível que a possibilidade de autodeterminação de uma pessoa - isto é, a possibilidade de ela escolher a forma de conduzir sua própria vida - é estritamente dependente de um mínimo de disponibilidade de recursos naturais. Basta que se pense nos danos naturais decorrentes de mudanças climáticas, como períodos de seca excessivamente longos, chuvas excessivas em regiões não adaptadas a essa situação, aquecimento de áreas com clima outrora ameno etc, para visualizar a dependência da ideia de autodeterminação com a necessidade de um "mínimo ambiental. Neste sentido, seguimos a conclusão de Patrick Ayala:

Considerando-se o conjunto dos argumentos analisados, e se é correto admitir que a sobrevivência e o livre desenvolvimento 
da personalidade das pessoas depende de que sejam garantidos ou mantidos determinados níveis de qualidade aos recursos naturais em geral, é possível atribuir à natureza a condição de bem que manifesta valor intrínseco, razão pela qual as ordens constitucionais contemporâneas, situadas que estão no contexto de projetos emancipatórios de qualidade diferenciada, tendem a reconhecer e a exprimir o valor de existência da natureza (e o valor de existência de outras formas de vida) como manifestação de um pluralismo moral na definição das tarefas estatais de proteção. ${ }^{47}$

\section{CONTEÚDO JURÍDICO DO PRINCÍPIO DA PRECAUÇÃO}

Há um sem número de trabalhos sociológicos - dentre os quais se destaca o de Ulrich Beck ${ }^{48}$ - dedicados a identificar e delinear a realidade do mundo moderno como um mundo de riscos e perigos criados pelo próprio desenvolvimento tecnológico e pela expansão das fronteiras do conhecimento em geral ${ }^{49}$. O desenvolvimento científico-tecnológico permitiu à humanidade desenvolver possibilidades de libertação e opressão nas mesmas proporções ${ }^{50}$, fazendo surgir riscos inimagináveis um século atrás ${ }^{51}$. Dentre os resultados desta realidade está a exigência de que sejam encontradas saídas psicológicas para conviver ${ }^{52} \mathrm{com}$ riscos de forma aceitável, isto é, conduzida de forma inconsciente ${ }^{53}$.

Dentre estes riscos nos interessa de forma particular um grupo que ameaça não apenas nosso modo de vida, mas talvez mesmo nossa forma de vida, nossa continuidade enquanto civilização. Falamos aqui dos riscos ambientais de grande porte, que vem sendo delineados de forma contínua pelas mais diversas entidades e autoridades nos últimos quarenta anos, pelo menos.

Sem muito esforço é possível pensar em algumas fontes de risco ambiental relevante que são produto imediato do desenvolvimento tecnológico, por exemplo, riscos decorrentes da engenharia genética aplicada a seres vivos e a alimentos, riscos decorrentes da queima de combustíveis fósseis, risco decorrentes da geração nuclear de energia, bem como dos testes de armamentos nucleares etc. Todos esses casos, com exceção do desenvolvimento de armas nucleares, estão numa zona cinzenta entre risco não mensurável e benefícios igualmente desconhecidos. Colocando de outra forma: todas estas situações geram riscos e benefícios aptos a melhorar nosso modo de vida, porém, expondo-o a riscos desconhecidos, isto é, cuja exata dimensão não é possível saber, não sendo possível, também, saber se poderíamos lidar com tais riscos caso se efetivem.

É bastante evidente que o discurso do desenvolvimento dentro de margens de segurança usualmente veiculado por aqueles que têm interesses (em geral econômicos) na continuidade da "evolução" tecnológica/industrial tem prevalecido, muitas vezes ocultando dados relevantes ${ }^{54}$, muitas vezes reforçando a crença numa suposta segurança dada pelo respeito a padrões científicos ${ }^{55}$. 
Neste cenário, um dos instrumentos desenvolvidos pelo Direito foi o "Princípio da Precaução", que ganhou particular importância com o surgimento das empresas de biotecnologia, vez que a abertura de capital de tais atores econômicos potencializa os riscos, já que a lógica do lucro tende a prevalecer sobre a contenção de riscos..$^{56}$

O princípio da precaução ganha identidade a partir da existência do potencial de risco de uma atividade. Com origem no Preâmbulo da Declaração Ministerial de Bremen de 1984, na Conferência Internacional sobre Proteção do Mar do Norte, foi mencionado e 1987, quando na Declaração Ministerial de Londres na II Conferência sobre o Mar do Norte, que o mencionou de modo específico. ${ }^{57}$

A fórmula mais conhecida, contudo, parece ser aquela que consta do documento final da conferência ECO 92, realizada no Rio de Janeiro, em seu "princípio 1558", que estabelece que havendo riscos ambientais, ainda que incertos, medidas de precaução a tais riscos deverão ser adotadas pelos Estados, não sendo a incerteza do risco um argumento válido para postergar medidas de proteção ambiental.

Considerada a supramencionada importância da proteção ambiental como verdadeiro direito fundamental ${ }^{59}$, torna-se imperativo resolver a questão da definição da norma que advém do Princípio da Precaução, vez que a indefinição - que é típica das ideias mais difundidas a respeito do termo "princípio", e que é corroborada pelo enunciado veiculado pela Declaração do Rio de Janeiro fragiliza o potencial deste dispositivo, tornando-o menos apto na concretização do direito a um meio ambiente equilibrado, tal como consta do caput do artigo 225 da Constituição brasileira de 1988, direito esse cuja proteção é atribuída a todos os entes da federação ${ }^{60}$.

Maurício Mota sintetiza boa parte dos problemas que decorrem do texto do "Princípio 15":

Nessa formulação alguns aspectos devem ser destacados. $\mathrm{O}$ primeiro é o de que a intensidade da tutela jurídica do bem (o meio ambiente) não é absoluta, mas circunscrita à capacidade de cada Estado; o segundo é o de que basta a ameaça hipotética, porém plausível de danos graves ou irreversíveis para justificar a intervenção, não sendo necessária a sua configuração concreta ou temporalmente provável; o terceiro aspecto é o de que não se exige a certeza científica absoluta da determinação do dano plausível, mas tão somente que este, dentro do conjunto de conhecimentos científicos na ocasião disponível, possa legitimamente se apresentar como potencialmente danoso e, finalmente, que as medidas econômicas a serem adotadas para prevenir a degradação ambiental sejam compatíveis com as outras considerações societárias do desenvolvimento econômico. ${ }^{61}$

Observa-se que há diversos pontos a serem resolvidos a fim de tornar tal instituto um instrumento efetivo de concretização do direito fundamental ao 
meio ambiente. Passemos agora à análise de cada um. Em seguida, outras questões devem ser abordadas, como a titularidade intergeracional do direito em tela.

É pacífica no meio jurídico a inexistência de direitos absolutos ${ }^{62}$. No elenco acima mencionado, a relativização do direito à efetivação plena do princípio da precaução foi relacionada "à capacidade de cada Estado". É possível ainda pensar nos casos de conflito normativo em que, argumentativamente, seja viável chegarmos a um impasse, uma situação que não pode ser decidida objetivamente, mas apenas por uma escolha que, ainda que juridicamente justificável, no fundo é reflexo das preferências daquele que decide. Estes dois problemas, contudo, podem ser manejados de forma satisfatória. Quanto ao último, nos parece evidente que a concretização da proteção ambiental tem uma preferência $a$ priori sobre qualquer outro direito. A razão disso é a sua essencialidade, no sentido de ser instrumento que protege não direitos individuais ou coletivos, mas, no limite, a viabilidade de nossa existência. Assim sendo, havendo conflito com outras normas, a precaução só deverá ser posta em segundo plano se surgir um conjunto de argumentos forte o bastante para isso e, ainda, que se demonstre que esta opção não ocasionará danos irreversíveis de grandes proporções.

Quanto à questão da capacidade de cada Estado, dois caminhos devem ser observados. Primeiro, é preciso garantir que todos os recursos possíveis (disponíveis) estão sendo utilizados em tal tarefa. Segundo, deve-se exigir dos Estados a imediata construção legislativa necessária à concretização do princípio, isto é, a criação de instrumentos jurídicos e instituições aptas a promover a concretização do mandamento ${ }^{63} \mathrm{em}$ estudo. É bem verdade que estas demandas esbarram na lógica política de agir conforme o potencial eleitoral das ações - que, no caso, é pequeno. A saída é trabalhar para que a proteção ambiental seja percebida cada vez mais como política de Estado, preferencialmente com respaldo em mecanismos internacionais que, não raramente, são uma contramedida efetiva ao agir estritamente eleitoreiro de boa parte da classe política.

Os segundo e terceiro problemas mencionados por Maurício Mota dizem respeito ao fato de que não é necessária a certeza do dano, mas apenas sua probabilidade, o que torna este, em nossa opinião, o maior dos problemas. Vejamos!

Embora as pesquisas das ciências exatas e biológicas já tenham abandonado a ideia da "certeza científica ${ }^{64}$ " há tempos, ${ }^{6566}$ o Direito - por paradoxal que pareça - ainda tem dificuldade em lidar com esse rompimento, e este é um exemplo típico desta dificuldade. Como determinar a (re)ação de instrumentos e instituições jurídicas sem conseguir definir, pelo menos, o momento em que a violação do preceito ocorreu?

Como o próprio princípio 15 da Declaração do Rio sugere, não é necessária a certeza científica, mas apenas a probabilidade. Logo, a resposta a esta questão talvez seja aprender a confiar naqueles que Thomas Kuhn ${ }^{67}$ designa "membros mais hábeis do grupo em cuja área de competência ele ocorre", isto é, naqueles considerados autoridades acadêmicas no tema que seja fonte de risco. 
É possível contra-argumentar que dentro da comunidade científica raramente há consensos, em especial quando estamos lidando com pesquisas que envolvem empresas privadas ou interesses econômicos de grande porte, públicos e/ou privados. Isto é inegável. Todavia, uma tomada de posição prudente recomendaria considerar - com mais afinco - as análises daqueles pesquisadores de carreira sem vínculos pessoais com o tema, e sem riscos de perder sua posição caso a conclusão seja no sentido de se suspender ou mesmo proibir o desenvolvimento de determinada tecnologia. Um bom exemplo é o caso do aquecimento global. No caso, há grande número de manifestos no sentido de que tal fenômeno não é reflexo de atuação humana, mas algo cíclico, da natureza do planeta. Por outro lado, há instituições como o IPCC - vinculado às Nações Unidas -, que congregam pesquisadores sem vínculos econômicos imediatos com o tema e que, portanto, merecem, em princípio, maior credibilidade.

Assim sendo, é possível concluir que a questão da incerteza é um problema mais cultural - talvez especificamente dos atores jurídicos - do que uma questão impeditiva da concretização da precautionary rule.

O último problema elencado diz respeito à compatibilidade da precaução com considerações sobre o desenvolvimento econômico ${ }^{68}$. Esta exigência é, no mínimo, curiosa. Todavia, o termo que melhor a descreve nos parece ser o relativismo de valores que vige neste começo de século XXI. Isto, pois, mesmo se tratando de riscos ainda não bem definidos, com potencial destrutivo eventualmente regional ou global - pense em energia nuclear ou organismos geneticamente modificados -, há quem questione os impactos econômicos da precaução!

É de clareza solar que a economia e suas diversas facetas é a característica mais relevante do mundo ocidental neste momento histórico. O que é preciso questionar são os limites, já bastante distendidos, até pela viabilidade deste modelo de forma de vida. Cogitar dos impactos da efetivação do princípio da precaução considerando os impactos que ele pode ter sobre a economia é inverter a mais elementar ordem de prioridade. Apesar de o que possa parecer numa visão mais superficial, não nos construímos em função da economia. Construimos a economia em função de nós! E assim deve ser, sob pena de chegarmos ao absurdo de dizer que é melhor aceitar um risco com potencial destrutivo desconhecido do que impedir que ele surja, pois isso seria prejudicial à economia. Basta considerar um caso concreto, o da usina nuclear de Fukushima, no Japão.

Embora num primeiro momento tenha sido considerado um risco aceitável, útil mesmo à economia local, ocorrido um desastre natural de grandes proporções a conclusão é a inversa, de que o risco que sua existência traz é maior do que seus benefícios.

Superados estes obstáculos anteriormente abordados, é preciso abordar a questão da titularidade do direito de exigir a imposição da postura determinada pelo instituto jurídico sob análise. 
Este item é importante por duas razões. Primeiro, porque sendo direito da chamada terceira dimensão - a dos ditos difusos e coletivos, também identificados como de "solidariedade" e de "fraternidade" ${ }^{69}$, há uma natural dificuldade em individualizar titulares e, com isso, portadores de legitimidade ativa para demandar sua implementação. Segundo, porque a efetivação da preservação ambiental deve ser orientada pela ideia de "equidade intergeracional" 70 , isto é, o fato de que o dever de proteger efetivamente o meio-ambiente existe não apenas em benefício da atual geração ${ }^{71}$, mas também das gerações futuras ${ }^{72}$.

A solução para esta questão, todavia, deve ser aquela da via que, a nós, parece a mais simples: a da atribuição de legitimidade a todos os potenciais envolvidos no eventual/possível dano, ainda que de forma reflexa ${ }^{73}$. O eventual risco de listisconsórcio multitudinário ou de proliferação de ações semelhantes em partes diversas do território nacional poderiam ser solucionados com a utilização dos instrumentos já utilizados nas ações que tutelam interesses difusos e coletivos.

Tudo considerado, é possível delinear o princípio da precaução como um instrumento que reconstrói as prioridades (valorativas) quando da tomada de decisões em situações de risco coletivo desconhecido, determinando que, apesar das demais considerações possíveis, a escolha a ser feita é a que de forma mais concreta reduza ou paralise os riscos, ainda que com prejuízos econômicos.

\section{CONCLUSÃO}

O desenvolvimento tecnológico e econômico tem empurrado a humanidade para fora de suas zonas de certeza. A busca por inovações e melhorias, com bastante frequência, nos faz caminhar rumo a fronteiras antes intransponíveis, nos colocando em situações cujas consequências estão, eventualmente, além de nossas capacidades de previsão e de resposta.

Para tais situações, e considerando o risco ambiental que elas criam - e, consequentemente, os riscos para as pessoas - surgiu o chamado "Princípio da Precaução", que determina que a ausência de certeza quanto ao risco de um evento não deve ser considerado um argumento válido para postergar a tomada de ações preventivas frente a este risco.

É verdade que uma norma jurídica qualquer não tem, sozinha, força suficiente para garantir aquilo que deseja garantir. Todavia, como visto, a exclusão do argumento da "incerteza científica" como premissa favorável à continuidade de pesquisas em áreas desconhecidas é tudo o que se pode e deve esperar do sistema jurídico, vez que este é seu limite "natural" enquanto sistema autopoiético.

De toda forma, sendo tal limite respeitado, ele será eficiente e suficiente para garantir a segurança ambiental necessária à manutenção da ideia de dignidade como possibilidade de escolher o próprio modo de vida. 


\section{REFERÊNCIAS}

AFONSO DA SILVA, Virgílio. Direitos Fundamentais: conteúdo essencial, restrições e eficácia. 2. ed. São Paulo: Malheiros Editores, 2010.

ALEXY, Robert. In: SILVA: Virgílio Afonso da (Trad). Teoria dos Direitos Fundamentais. São Paulo: Malheiros Editores, 2008.

ALVES, Cândice Lisbôa. Direito à Saúde: efetividade e proibição do retrocesso social. Belo Horizonte: Editora D’Plácido, 2013.

AYALA, Patrick de Araújo. Direito Ambiental de Segunda Geração e o Princípio da Sustentabilidade na Política Nacional do Meio Ambiente. In: Revista de Direito Ambiental - RDA, v. 63, p. 103-132, 2011.

BAUMAN, Zygmunt. In: MEDEIROS, Carlos Alberto (Trad.). Medo Líquido. Rio de Janeiro: Jorge Zahar Ed., 2008.

BENJAMIN, Antonio Herman V.; MARQUES, Claudia Lima; BESSA, Leonardo Roscoe. Manual de Direito do Consumidor. 5. ed. São Paulo: Editora Revista dos Tribunais, 2013.

CAFFERATTA, Néstor A. El Principio Precautorio. In: Gaceta Ecológica, n. 73, pp.05-21, 2004.

CLAM, Jean. A Autopoiese no Direito. In: ROCHA, L.S.; SCHWARTZ, G.; CLAM, J. Introdução à Teoria do Sistema Autopoiético do Direito. Porto Alegre: Livraria do Advogado Ed., 2005.

COMPLAK, Krystian. Cinco teses sobre a dignidade da pessoa humana como conceito jurídico. In: Revista da Esmec. v.15, n.21, 2008.

DELATTRE, Pierre. In: FURTADO, José Afonso (Trad.). Teoria dos Sistemas e Epistemologia. Lisboa: A Regra do Jogo Edições, 1981.

DINO NETO, Nicolao. Introdução ao Estudo das Infrações Administrativas Ambientais. In: Revista de Direito Ambiental - RDA, v. 62, pp.169-200, 2011.

EAGLEMAN, David. In: VINAGRE, Ryta (Trad.). Incógnito: as vidas secreta do cérebro. Rio de Janeiro: Rocco, 2012.

GIDDENS, Anthony. In: FIKER, Raul (Trad.). As consequências da modernidade. São Paulo: Editora UNESP, 1991.

KING, Michael. A verdade sobre a autopoiese no direito. In: ROCHA, L. S.; KING, M.; SCHWARTZ, G. A Verdade sobre a Autopoiese no Direito. Porto Alegre: Livraria do Advogado Ed., 2009.

KUHN, Thomas S. In: BOEIRA, Beatriz Vianna; BOEIRA, Nelson (Trad). A Estrutura das Revoluções Científicas. 10. ed. São Paulo: Perspectiva, 2011. 
LOPEZ, Myriam Sepulveda. La Dignidad Humana como un valor etico juridico implicado en la Bioetica y el Bioderecho. In: Mission Jurídica: Revista de Derecho y Ciencias Sociales. n. 2. 2009.

LUHMANN, Niklas. In: BAYE, Gustavo (Trad.). Sociologia do Direito I. Rio de Janeiro: Edições Tempo Brasileiro, 1983.

. In: NASSER, Ana Cristina Arantes (Trad.). Introdução à Teoria dos

Sisteas. 2. ed. Petrópolis, RJ: Vozes, 2010.

MENDONÇA, Daniel; RODRIGUES, Léo Peixoto. Laclau e Luhmann: um diálogo possível. In: MENDONÇA, D.; RODRIGUES, L. P. (Orgs.). Ernesto Laclau \& Niklas Luhmann: pós fundacionismo, abordagem sistêmica e as organizações sociais. Porto Alegre: EDIPUCRS, 2006.

MOTA, Maurício. Princípio da precaução no direito ambiental: uma construção a partir da razoabilidade e da proporcionalidade. In: Revista de Direito Ambiental - RDA, v.50, pp.180-211, 2008.

NEVES, Marcelo. Entre Têmis e Leviatã: uma relação difícil. 2. ed. São Paulo: Martins Fontes, 2008.

. Transconstitucionalismo. São Paulo: Editora WMF Martins Fontes, 2009.

ROCHA, Leonel Severo. Da epistemologia jurídica normativista ao construtivismo sistêmico. In: ROCHA, L.S.; SCHWARTZ, G.; CLAM, J. Introdução à Teoria do Sistema Autopoiético do Direito. Porto Alegre: Livraria do Advogado Ed., 2005.

SAMPAIO, José Adércio Leite. Direitos Fundamentais. 2. ed. Belo Horizonte: Editora Del Rey, 2010.

SCHABER, Peter. Menschenwürde und Selbstachtung. Ein Vorschlag zum Verständnis der Menschenwürde, in: Studia Philosophica, v. 63, p. 93-106, 2004.

SCHWARTZ, Germano. A Fase Pré-autopoiética do Sistemismo Luhmanniano. In: ROCHA, L.S.; SCHWARTZ, G.; CLAM, J. Introdução à Teoria do Sistema Autopoiético do Direito. Porto Alegre: Livraria do Advogado Ed., 2005.

SCHWARTZ, Germano. Autopoiese e direito: auto-observações e observações de segundo grau. In: ROCHA, L. S.; KING, M.; SCHWARTZ, G. A Verdade sobre a Autopoiese no Direito. Porto Alegre: Livraria do Advogado, 2009.

SILVA, Reinaldo Pereira e. A teoria dos direitos fundamentais e o ambiente natural como prerrogativa humana individual. In: Revista de Direito Ambiental - RDA, v. 46, pp.164-190, 2007.

TEIXEIRA, Ricardo Augusto de Araújo. Direito Penal de Emergência. Belo Horizonte: Editora D’Plácido, 2013.

WETZ, Franz Josef. Menschenwürde: Eine Illusion? Klett-Cotta Verlag, Stuttgart, 2005. 
1 SILVA, Reinaldo Pereira e. A teoria dos direitos fundamentais e o ambiente natural como prerrogativa humana individual. In: Revista de Direito Ambiental - RDA, v. 46, pp.164-190, 2007.

2 Ibid., p. 165.

3 WETZ, Franz Josef. Menschenwürde: Eine Illusion? Klett-Cotta Verlag, Stuttgart, 2005, p. 28

4 No original: Allgemein wird den Begriff Menschenwürde auf zweierlei Weise verwendet: einmal als Bezeichnung einer angeborenen Eigenschaft des Menschen, welche Wesensmerkmal gennant wird. Hiernach besitzt der Einzelne schon kraft seines Menschseins, unabhängig von seinen Verhalten und den gesellschaftlichen Verhältnissen, in denen er lebt, eine besondere Würde. Dann aber bedeutet Würde auch einen Gestaltungsauftrag, demzufolge es hauptsächlich von uns Menschen selbst, unserer Lebensweise un unseren Umgangsformen abhängt, ob und inwiefern wir Würde besitzen. In diese Zusammenhang wird Würde mal als individuelles Verdienst, mal als gesellschaftliche Leistung betrachtet. (WETZ, op. cit., p.28).

5 TEIXEIRA, Ricardo Augusto de Araújo. Direito Penal de Emergência. Belo Horizonte: Editora D’Plácido, 2013.

6 Na realidade, aquilo a que se chama Teoria dos sistemas recobre todo o conjunto de tentativas, provenientes de horizontes muito diferentes, utilizando conceitos e princípios de formalização não menos diversos, mas tendo todas em comum o facto de procurarem atingir os objectivos que acima lembrámos em domínios de estudo mais ou menos amplos. (...). (DELATTRE, Pierre. In: FURTADO, José Afonso (Trad.). Teoria dos Sistemas e Epistemologia. Lisboa: A Regra do Jogo Edições, 1981, p.12).

7 (...) $\mathrm{O}$ instrumental da pesquisa sociológica que então começava a desenvolver-se apresentava exigências teóricas que não mais podiam ser satisfeitas com as antigas concepções globalizantes da totalidade social. A teoria da sociedade como totalidade abrangente do convívio social desmoronou. Isso bloqueou também o desenvolvimento da sociologia do direito, ou, pelo menos, a desviou no sentido do que era possível metodologicamente, transformando-a em uma sociologia dos papéis profissionais, dos processos decisórios, etc...ou seja em uma sociologia cujo tema não era mais o direito. (LUHMANN, Niklas. In: BAYE, Gustavo (Trad.). Sociologia do Direito I. Rio de Janeiro: Edições Tempo Brasileiro, 1983, p.167).

8 Portanto, a sociedade é comunicação. E tudo o que se comunica faz parte da sociedade ou é sociedade. A sociedade é uma realidade com clausura autoreferencial ordenada de forma autosubstitutiva, de vez que tudo que deve ser substituído ou mudado, em seu interior, deve ser mudado ou substituído a partir de seu próprio interior. É assim que a sociedade se comunica, se transforma e se complexifica. Dessa forma, a sociedade é tida como o sistema global da comunicação. E a comunicação é a síntese da informação, do ato de comunicação e da compreensão. Ou, como lembra Leonel Severo Rocha, comunicação é a capacidade de repetir as suas operações diferenciando-as de suas observações. (SCHWARTZ, op. cit., p.71) (itálicos no original).

9 Por isso, a teoria de Luhmann é uma concepção de mundo que pode ser chamada, na falta de outro nome, pós-moderna. Teoria que acentua não a racionalidade, não o consenso, a identidade, mas a produção da diferença, da fragmentação, da singularidade. É uma teoria crítica nesse sentido avançando o máximo possível além de qualquer noção de racionalidade tradicional. É claro que continua aproveitando um pouco das contribuições de Weber e de Parsons, mas a sociedade, na perspectiva de Luhmann, é uma sociedade que visa à produção da diferença. Introduziu-se toda essa trajetória para se salientar a importância da teoria sociológica do Direito. Weber colocou a problemática da ação, da decisão; Parsons, a problemática dos sistemas. E Luhmann vai rever tudo isso e aprofundar numa teoria da sociedade contemporânea. (ROCHA, Leonel Severo. Da epistemologia jurídica normativista ao construtivismo sistêmico. In: ROCHA, L.S.; SCHWARTZ, G.; CLAM, J. Introdução à Teoria do Sistema Autopoiético do Direito. Porto Alegre: Livraria do Advogado Ed., 2005, p. 30).

10 (...) Na diferenciação segmentária são formados diversos sistemas iguais ou semelhantes: a sociedade compõe-se de diversas famílias, tribos, etc. Na diferenciação funcional os sistemas parciais, ao contrário, são formados para exercerem funções especiais e específicas, sendo portanto distintos entre si: para a política e a administração, para a economia, para a satisfação de necessidades religiosas, para a educação, para cuidar dos doentes, para funções familiares residuais (assistência, socialização, recreação), etc. Uma paulatina transformação da diferenciação segmentária para a diferenciação funcional nas mais importantes áreas funcionais da sociedade constitui, genericamente, um traço básico do desenvolvimento social. (...). (LUHMANN, op. cit., p. 176).

11 (...) a função do direito reside na sua eficiência seletiva, na seleção de expectativas comportamentais que possam ser generalizadas em todas as dimensões. O direito é assim "a estrutura de um sistema social que se baseia na generalização congruente de expectativas comportamentais normativas". O direito, para Luhmann, embora visto como uma estrutura, é dinâmico devido à permanente evolução provocada pela sua necessidade de constantemente agir como uma das estruturas sociais redutoras da complexidade das possibilidades do ser no mundo. Assim, esta complexidade heterogênea, causado pela chamada dupla contingência é combatida pelos processos de identificação estrutural, somente possiveis com a criação de 
diferenciações funcionais. A teoria sistêmica do direito, comunicando a norma jurídica com o social e a práxis significativa, fornece um importante passo para que a construção de uma nova teoria do direito aborde simultaneamente os seus aspectos analíticos, hermenêuticos e pragmáticos, em relação com o sistema social. (ROCHA, op. cit., p. 32).

12 A complexidade é, então, reconstruída a partir de outro prisma: a de sua redução. É sua redução que, paradoxalmente, permite a evolução social, e mais: é o que permite toda a origem da interação social. No entanto, o problema da interação social não pode ser embasado na hipótese de que a complexidade se dá quando dois indivíduos se comunicam. Deve-se entender o problema da contingência não somente como um problema a ser enfrentado, mas como uma questão que gera maiores possibilidades para sua própria resolução. (SCHWARTZ, op. cit., p.69).

13 O conceito de autopoiese tem sua origem na teoria biológica de Maturana e Varela. Etimologicamente, a palavra deriva do grego autós ("por si próprio") e poiesis ("criação", "produção"). Significa inicialmente que o respectivo sistema é construído pelos próprios componentes que ele constrói. Definem-se então os sistemas vivos como máquinas autopoiéticas: uma rede de processos de produção, transformação e destrução de componentes que, através de suas interações e transformações, regeneram e realizam continuamente essa mesma rede de processos, constituindo-a como unidade concreta no espaço em que se encontram, ao especificarem-lhe o domínio topológico de realização. Trata-se, portanto, de sistemas homeostáticos, caracterizados pelo fechamento na produção e reprodução dos elementos. (...). (NEVES, Marcelo. Entre Têmis e Leviatã: uma relação difícil. 2. ed. São Paulo: Martins Fontes, 2008, p. 60-61).

14 (...) a autopoiese é essencialmente uma problemática de continuação (Kontinuierung), no tempo, na efetuação (Vollzug), operação após operação ou acontecimento após acontecimento, de um sistema, ou seja, de uma performance funcional que se tornou autolimitante (i.e. Autônomo). Isso porque encontraremos no centro da concepção autopoietológica os conceitos de autorreferência, de recursividade, de conectividade ou conectabilidade. A autopoiese pode, mesmo, ser definida simplesmente como a qualidade de um sistema "que organiza a conectabilidade" (por seus elementos). Esse sistema permite, dessa maneira, as operações reprodutivas sobre a base recursiva das operações que as precedem. Um sistema pratica a autopoiese desde o momento em que ele é capaz de encadear as operações perfeitamente genuínas e indiferenciáveis de suas próprias operações. (CLAM, Jean. A Autopoiese no Direito. In: ROCHA, L.S.; SCHWARTZ, G.; CLAM, J. Introdução à Teoria do Sistema Autopoiético do Direito. Porto Alegre: Livraria do Advogado Ed., 2005, p.102-103).

15 O primeiro ponto a ser afirmado é que o direito na teoria autopoiética se refere, como já vimos, a um sistema de sentido, e não a estruturas institucionais formais. Os limites do direito não são determinados nem pelas paredes do tribunal nem pelo alcance de seu longo braço, mas pela aplicação ao ambiente externo do código legal/ ilegal. O direito só existe como comunicações jurídicas. Em segundo lugar, a teoria não nega a possível influência de outros sistemas sociais - políticos, econômicos, religiosos etc. - sobre o conteúdo das comunicações jurídicas, mas refuta a possibilidade de esses sistemas determinarem as comunicações jurídicas de forma direta ou previsível. Rejeita, por conseguinte, tanto a crença ingênua do realismo jurídico nos fatores sociopsicológicos como determinantes das decisões judiciais quanto a determinação política alegada por alguns juristas. (KING, op. cit., p.88).

16 Menos trivial, e talvez até surpreendente, é o fato de que o sistema não pode empregar suas próprias operações para entrar em contato com o meio. Pode-se dizer que este último constituiria a especificidade do conceito de encerramento operativo. As operações são acontecimentos que apenas surgem no sistema, e não podem ser empregados para defender ou atacar o meio. No plano das operações específicas do sistema, não há nenhum contato com o meio; sendo que isso também será válido, quando - e sobre este difícil princípio, que contradiz toda a tradição da teoria do conhecimento, é preciso chamar expressamente a atenção - as referidas operações forem observações, ou bem, operações. Além disso, tampouco para os sistemas que observam existe, no plano de sua operação, algum contato com o meio. (...). (LUHMANN, op. cit., p.102-103).

17 O Direito é visto como uma sistema comunicativo que produz normas de conduta tanto para suas próprias operações quanto para a sociedade em geral. Como tal, é fechado no sentido de que não pode produzir nada a não ser Direito e também no sentido de que suas operações são impermeáveis a comunicações diretas de outros sistemas sociais. Isso não quer dizer que a legislação ou as decisões dos juízes estejam à margem de qualquer influência de fatores políticos ou econômicos. O que a teoria autopoiética propõe, mais exatamente, é que o sistema jurídico é fechado normativamente, mas aberto cognitivamente. Trata-se, como Teubner enigmaticamente nos diz, "aberto de uma forma fechada"(!). (KING, op. cit., p. 88).

18 Nunca se deve perder de vista que o acoplamento estrutural é compatível com a autopoiesis, e que, por conseguinte, há possibilidades de influir no sistema, desde que não se atente contra a autopoiesis. Isso pode ser formulado de modo inverso: a linha de demarcação que divide o meio, entre aquilo que estimula ao sistema e aquilo 
que não o estimula - e que se realiza mediante o acoplamento estrutural -, tende a reduzir as relações relevantes entre sistema e meio a um âmbito estreito de influência. Apenas desse modo, um sistema pode transformar irritações em causalidade. (LUHMANN, op. cit., p. 132).

19 Esse acoplamento serviria à promoção e filtragem de influências e instigações recíprocas entre sistemas autônomos diversos, de maneira duradoura, estável e concentrada, vinculando-os no plano de suas respectivas estruturas, sem que nenhum desses sistemas perca a sua respectiva autonomia. Os acoplamentos estruturais são filtros que excluem certas influências e facilitam outras. (...) As estruturas de um sistema passam a ser, mediante os acoplamentos estruturais, relevantes e mesmo indispensáveis à reprodução das estruturas de um outro sistema e vice-versa. (NEVES, op. cit., p.35).

$20 \mathrm{O}$ sistema pode reagir a irritações e estímulos (perturbações, na linguagem de Maturana), não quando tudo pode influir no sistema, mas somente quando existem padrões altamente seletivos. Ou seja, o sistema reage apenas quando pode processar informação e transformá-la em estrutura. As irritações surgem de uma confrontação interna (não especificada, num primeiro momento) entre eventos do sistema e possibilidades próprias, que consistem, antes de tudo, em estruturas estabilizadas, expectativas. Portanto, não existe nenhuma irritação no meio do sistema, assim como não existe transfer de irritação do meio ao sistema. Trata-se sempre de uma construção própria do sistema; é sempre uma autoirritação (naturalmente posterior a influxos provenientes do meio). (LUHMANN, op. cit., p.132).

21 Para Luhmann, tanto a sociedade como o indivíduo devem ser vistos como sistemas. A sociedade constitui-se num sistema social e o(s) indivíduo(s) em sistema(s) psíquico(s). Os sistemas, em Luhmann, são incomunicáveis diretamente. Para um sistema autorreferenciado, tudo o que não for ele mesmo é meio ambiente, inclusive os demais sistemas, imaginando-se um sistema-mundo. (...).(MENDONÇA, Daniel; RODRIGUES, Léo Peixoto. Laclau e Luhmann: um diálogo possivel. In: MENDONÇA, D.; RODRIGUES, L. P. (Orgs.). Ernesto Laclau \& Niklas Luhmann: pós fundacionismo, abordagem sistêmica e as organizações sociais. Porto Alegre: EDIPUCRS, 2006, p. 93).

22 TEIXEIRA, 2013.

23 Ensina Myriam Sepulveda Lopez que para Aristóteles todo ser capaz de movimentar-se tem alma. Existiriam, porém, três tipos de alma: a vegetativa, a irracional e a racional. $\mathrm{O}$ ser humano seria o único dotado de alma racional, aquela que permite pensar. Daí situar-se num plano superior aos demais seres, possuidores das outras espécies de alma. (LOPEZ, op. cit).

24 Ibid., p. 110.

25 No original: (...) el ser humano se eleva por encima de las otras entidades del mundo, por el hecho de tener alma racional. (LOPEZ, op. cit., p.110).

26 Ibid., p.110

27 No original: (...) en el pensamiento judio, el ser humano se alza por encima de todas las criaturas, por el hecho de ser imagen y semejanza de Dios. (Ibid., p.110).

28 Ibid.

29 WETZ, op. cit., p.29.

30 No original: Würde - dignitas ex excellentia - galt damals nicht als angeborene Eigenschaft, sondern allein als das Ergebnis individueller Leistung und sozialer Anerkennung. (WETZ, op. cit., p. 29).

31 WETZ, op cit., p. 30,

32 No original: Als Gottes Kind und Ebenbild besitze der Mensch einen absoluten Wert, wodurch er sich von allen übrigen Kreaturen unterscheide. (WETZ, op. cit., p.30).

33 WETZ, op. cit., p.31,

34 No original: So gründete beispielsweise Immanuel Kant im 18. Jahrhundert die Würde des Menschen ausschiließlich auf dessen Selbstbewusstsein, Freiheit, Moralität und Vernunft - und gerade nicht auf die menschliche Gottebenbildlichkeit und Stellung in der Welt. (WETZ, op. cit., p.31).

35 SCHABER, Peter. Menschenwürde und Selbstachtung. Ein Vorschlag zum Verständnis der Menschenwürde, in: Studia Philosophica, v. 63, p. 93-106, 2004.

36 Ibid.

37 No original: (...) Für die Zuschreibung von Menschenwürde könnte dabei unterschiedliche Gründe eine Rolle spielen. So könnte der Umstand relevant sein, dass wir uns den anderen verbunden fühlen ode dass sie zur selben Gattung gehören. (...) Dieser Vorschlag sagt nichts darüber aus, wo die Grenze der Würdezuschreibung genau zu ziehen ist. Diese Grenzziehung wird vielmehr von den diesbezüglich gesellschaftlich relevanten Überleugungen abhängig gemacht. (...). (SCHABER, op. cit., p. 97).

38 SCHABER, op. cit.

39 Ibid., p. 99. 
40 No original: (...) Auf diese Weise ist die inhärente Würde eines Menschen nicht abhängig von der sozialen Anerkennung eines Menschen als Trägers von Würde, sondern von der Eigenschaft, diese Fähigkeit zu haben. (SCHABER, op. cit., p. 99).

41 Ibid.

42 Ibid.

43 Tradução literal do título do capitulo: Meschenwürde als Recht, nicht erniedrigt zu werden. É preciso considerar que o verbo erniedrigen pode ser traduzido de outras formas, como "diminuir", "rebaixar", "desconsiderar". Optamos por "humilhar" por entendermos que representa de forma mais completa todas as ideias que o autor expõe.

44 SCHABER, op. cit., p. 104,

45 No original: Die Betrachtung dieser paradigmatischen Beispiele von Würdeverletzungen legt die folgende Konzeption von Menschenwürde nahe: Menschenwürde ist kein physisches Gut, sondern ein moralischer Anspruch, der verletzt wird, wenn eine Person ernidrigt wird. Einem Menschen Würde zuzusprechen, bedeutet demnach, ihm das moraslische Recht zuzuerkennen, nicht erniedrigt zu werden. Jede Person hat, weil und insofern sie als Träger von Menschenwürde aufgefasst wird, einen berechtigen Anspruch, von anderen in einer bestimmten Weise behandelt zu werden bzw. in einer bestimmten Weise leben zu könneni. (SCHABER, op. cit., p.104).

46 COMPLAK, op. cit.

47 AYALA, Patrick de Araújo. Direito Ambiental de Segunda Geração e o Princípio da Sustentabilidade na Política Nacional do Meio Ambiente. In: Revista de Direito Ambiental - RDA, v. 63, p. 103-132, 2011, p.109.

48 Neste contexto, Beck visualiza uma dimensão perigosa para o desenvolvimento, especialmente considerando a função da ciência, do conhecimento e da tecnologia. As consequências do desenvolvimento científico e industrial são o perigo e o risco, que vêm acompanhados da possibilidade de catástrofes e resultados imprevisíveis na dimensão estruturante da sociedade. Nessa situação de incerteza - de riscos e perigos potencializados e multifacetados - que se inserem as discussões sobre o princípio da precaução. (MOTA, op. cit, p.181).

49 Daí, portanto, a constatação de que o risco não é algo que deva ser temido. Ao contrário. Ele é parte imanente do sistema social. É condição para seu desenvolvimento, pois, conforme Giddens, o risco é a dinâmica mobilizadora de uma sociedae propensa à mudança, que deseja determinar seu próprio futuro em vez de confiá-lo à religião, à tradição ou aos caprichos da natureza. Torna-se necessário, assim, perceber a inserção do sistema jurídico nessa realidade. (SCHWARTZ, op. cit., p.121).

50 (...) A modernidade, como qualquer um que vive no final do século XX pode ver, é um fenômeno de dois gumes. O desenvolvimento das instituições sociais modernas e sua difusão em escala mundial criaram oportunidades bem maiores para os seres humanos gozarem de uma existência segura e gratificante que qualquer tipo de sistema pré-moderno. Mas a modernidade tem também um lado sombrio, que se tornou muito aparente no século atual. (GIDDENS, Anthony. In: FIKER, Raul (Trad.). As consequências da modernidade. São Paulo: Editora UNESP, 1991, p.16).

51 A realidade dos atuais problemas ambientais encontra-se muito bem representada pelos efeitos das mudanças climáticas globais: efeitos imprevisíveis, de larga escala, invisíveis, de grande potencial ofensivo, e que redefinem este contexto de uma sociedade de riscos, uma sociedade que é contemporânea e que reforça os liames de solidariedade e de corresponsabilidade de tal modo que nunca se teve notícia anterior. (AYALA, 2011, p.106).

52 A vida líquida flui ou se arrasta de um desafio para outro e de um episódio para outro, e o hábito comum dos desafios e episódios é sua tendência a terem vida curta. Pode-se presumir o mesmo em relação à expectativa de vida dos medos que atualmente afligem as nossas esperanças. Além disso, muitos medos entram em nossa vida juntamente com os remédios sobre os quais muitas vezes você ouviu falar antes de ser atemorizado pelos males que esses prometem remediar. (...) (BAUMAN, op. cit., p. 14).

53 (...) Nossas esperanças, sonhos, aspirações, medos, instintos cômicos, ótimas ideias, fetiches, senso de humor e desejos surgem deste órgão estranho - e quando o cérebro muda, mudamos nós. Assim, embora seja fácil intuir que os pensamentos não têm base física, que são algo como plumas ao vento, na realidade eles dependem diretamente da integridade do enigmático centro de controle de um quilo e trezentos. A primeira lição que aprendemos no estudo de nossos circuitos é simples: a maior parte do que fazemos e sentimos não está sob nosso controle consciente. (...). (EAGLEMAN, op. cit., p. 12)

54 Os desenvolvimentos modernos não poderiam ter ocorrido e com toda certeza não conseguiriam avançar no ritmo que adquiriram se a questão dos limites espaciais "naturais" e intransponíveis não fosse explicada de maneira conveniente e ativamente reprimida, ou simplesmente afastada da vista ao ser riscada da lista dos fatores incluídos nos cálculos instrumentais-racionais. Eles não seriam iniciados, e se o fossem teriam sido prontamente interrompidos, se os limites da sustentabilidade do planeta tivessem sido reconhecidos e admitidos, seriamente considerados e respeitados, e caso se tivesse feito mais do que discursos ocasionais da boca para fora em relação ao preceito da universalidade e da igualdade entre os seres humanos. (...) (BAUMAN, op. cit., p. 98). 
55 Uma parte básica de meu argumento será a de que a natureza das instituições modernas está profundamente ligada ao mecanismo da confiança em sistemas abstratos, especialmente confiança em sistemas peritos. Em condições de modernidade, o futuro está sempre aberto, não apenas em termos da contingência comum das coisas, mas em termos da reflexividade do conhecimento em relação ao qual as práticas sociais são organizadas. (...) A fidedignidade conferida pelos atores leigos aos sistemas peritos não é apenas uma questão - como era normalmente o caso no mundo pré-moderno - de gerar uma sensação de segurança a respeito de um universo de eventos independentemente dado. É uma questão de cálculo de vantagem e risco em circunstâncias onde o conhecimento perito simplesmente não proporciona esse cálculo, mas, na verdade, cria (ou reproduz) o universo de eventos, como resultado da contínua implementação reflexiva desse próprio conhecimento. (GIDDENS, op. cit., p. 87-88).

56 SOUZA; SOUZA, op. cit.

57 Ibid., p. 186.

58 La Declaración de Rio de Janeiro, aprobada por la Conferencia de las Naciones Unidas sobre el Medio Ambiente y el Desarollo, en junio de 1992, consagró el Principio Precautorio, bajo el siguiente texto: "Princípio 15: Con el fin de proteger el medio ambiente, los Estados deberán aplicar ampliamente el criterio de precaución conforme a sus capacidades. Cuando haya peligro de daño grave e irreversible, la falta de certeza científica absoluta no deberá utilizarse como razón para postergar la adopción de medidas eficaces en función de los costos para imedir la degradación del medio ambiente". (CAFFERATTA, Néstor A. El Principio Precautorio. In: Gaceta Ecológica, n. 73, pp.05-21, 2004, p. 6).

59 (...) Segundo Michel Prieur, "não se pode dissociar o homem de seu ambiente de vida e dos elementos sócio-culturais e biológicos que o compõem”, pois o desenvolvimento da vida humana ocorre ambientalmente. Assim sendo, a fundamentalidade do direito ao ambiente natural expressa-se na garantia de sua qualidade como condição imprescindível ao desenvolvimento das potencialidades individuais. (SILVA, op. cit., p.181).

60 Em relação ao meio ambiente, a Constituição Federal - núcleo definidor da "competência das competências" estabelece a competência administrativa comum da União, dos Estados, do Distrito Federal e dos Municípios para proteger o meio ambiente, referindo-se, ainda, de forma redundante, ao combate à poluição e à preservação das florestas, da fauna e da flora (art. 23, VI e VII, da CF/1988). (DINO NETO, Nicolao. Introdução ao Estudo das Infrações Administrativas Ambientais. In: Revista de Direito Ambiental - RDA, v. 62, pp.169-200, 2011, p. 191).

61 MOTA, op. cit., p.181.

62 Assim abriu seu voto na Medida Liminar na ADI 2.556-0-DF, em 2002, o Min. Marco Aurélio: "Todos temos a convicção de que não há direitos absolutos na Carta da República. Nem mesmo aquele à vida existe, já que a carta excepciona a proibição da pena de morte, fazendo-o na hipótese da guerra".

63 Nessa situação parece satisfatória a ideia de princípios de Robert Alexy: "(...) princípios são normas que ordenam que algo seja realizado na maior medida possível dentro das possibilidades jurídicas e fáticas existentes. Princípios são, por conseguinte, mandamentos de otimização, que são caracterizados por poderem ser satisfeitos em graus variados e pelo fato de que a medida devida de sua satisfação não depende somente das possibilidades fáticas, mas também das possibilidades jurídicas.”. (ALEXY, op. cit., p. 90). E continua a explicação Virgílio Afonso da Silva: “(...) A ideia regulativa é a realização máxima, mas esse grau de realização somente pode ocorrer se as condições fáticas e jurídicas forem ideais, o que dificilimente ocorre nos casos difíceis. Isso porque, ainda que nos limitemos apenas às condições jurídicas, dificilmente a realização total de um princípio não encontrará barreira na proteção de outro princípio ou de outros princípios.”. (SILVA, op. cit., p. 46).

64 (...) A ciência normal, atividade na qual a maioria dos cientistas emprega inevitavelmente quase todo seu tempo, é baseada no pressuposto de que a comunidade científica sabe como é o mundo. Grande parte do sucesso do empreendimento deriva da disposição da comunidade para defender esse pressuposto - com custos consideráveis, se necessário. Por exemplo, a ciência normal frequentemente suprime novidades fundamentais, porque estas subvertem necessariamente seus compromissos básicos. Não obstante, na medida em que esses compromissos retêm um elemento de arbitrariedade, a própria natureza da pesquisa normal assegura que a novidade não será suprimida por muito tempo. (...) Desta e de outras maneiras a ciência normal desorienta-se seguidamente. E quando isto ocorro - isto é, quando os membros da profissão não podem mais esquivar-se das anomalias que subvertem a tradição existente da prática científica - então começam as investigações extraordinárias que finalmente conduzem a profissão a um novo conjunto de compromissos, a uma nova base para a prática da ciência. (KUHN, op. cit., p.24).

65 Há muito a filosofia da ciência abandonou o pressuposto de que, para termos teorias científicas que cumpram suas funções explicativa e preditiva, é preciso exigir uma certeza absoluta. Em ciência não há fundamentos últimos ou teorias não-falseáveis: o conhecimento científico é, em consequência, dinâmico. Podemos concluir que a certeza enquanto propriedade de uma observação, de uma lei, de uma teoria ou de uma previsão nunca é absoluta, mas sempre relativa a um conhecimento de fundo, aceito em caráter provisório e submetido constantemente à crítica. (MOTA, op. cit., p.196). 
66 KUHN, op. cit.

67 Ibid.

68 Sustein e Holmes são expoentes americanos da referida análise [análise econômica do direito] e desenvolveram, pioneiramente, a teoria dos custos dos direitos. Segundo essa teoria, o exercício da atividade pública é dependente da captação de recursos, o que é feito por intermédio da arrecadação tributária, sendo esta a fonte de custeio das atividades públicas. Sustein e Holmes esclarecem que todos os direitos, sejam os positivos, sejam os negativos, implicam custos para o Estado e que apenas se poderá 'levar os direitos a sério' se for considerada a escassez de recursos também como variável significante. (...). (ALVES, op. cit., p.103).

69 SAMPAIO, José Adércio Leite. Direitos Fundamentais. 2. ed. Belo Horizonte: Editora Del Rey, 2010, p.273.

70 (...) A fraternidade embandeirada pela nova geração inspirou adicionalmente a ideia de que somos todos habitantes de um mesmo e frágil mundo a exigir um concerto universal com vistas a manter as condições de habitabilidade planetária para as presentes e futuras gerações. Tem-se a afirmação do direito ao desenvolvimento sustentável e ao meio-ambiente ecologicamente equilibrado; tanto quanto, para alguns, incluem-se os direitos que contextualizam no plano global a proteção à saúde, de modo a tornar acessíveis, sem as barreiras das patentes, remédios para doenças graves como a AIDS. (SAMPAIO, op. cit., p.274).

71 A afirmação politica e normativa de um objetivo de solidariedade e um compromisso com as gerações presentes e futuras, como os que se encontram expressos nos arts. 3ํ, 1, e 225, caput, da CF/1988, impõe a sujeição do Estado e dos particulares ao dever de autorrestrição no livre exercício da autonomia da vontade. (AYALA, op. cit., p.108).

72 (...) Há uma crescente preocupação de que as mudanças globais podem ter como efeito a redução da parte da riqueza e diversidades globais a que cada habitante do mundo tem acesso ou terá no futuro. O suposto conteúdo desses direitos, haurido de instrumentos legais internacionais, é o de direitos que cada geração tem em beneficiar-se e em desenvolver o patrimônio natural e cultural herdado das gerações precedentes, de tal forma que este possa ser passado às gerações futuras em circunstâncias não piores do que as recebidas. (MOTA, op. cit., p.182).

73 Entendido como forma reflexa aquilo que a melhor doutrina consumerista identifica com o termo bystander, isto é, todos aqueles que, embora não participem diretamente da atividade, são vítimas dela. (BENJAMIN; MARQUES; BESSA, op. cit.).

\title{
DIGNITY AND UMWELT: SYSTEMIC FOUNDATIONS OF THE PRINCIPLE OF PRECAUTION OVER THE ENVIRONMENT
}

\begin{abstract}
The current paper aims to find out whether Systems Theory can contribute to the development of the principiological reasoning of Environmental Law. From a short display of the Systems Theory structure - in its lumanian shape - the study of the precautionary rule is reached. In this context, another purpose is to investigate if such principle can be substantiated by the idea of Human Dignity, due to the fact that such idea should rule the entire legal system.
\end{abstract}

Key-words: Precaution. Environmental Principiology. Systems Theory.

Submetido: 19 nov. 2015

Aprovado: 5 jan. 2016 